\title{
Vaginal Amebiasis Mimicking Cervical Cancer
}

\author{
Masayuki Ota and Naoki Yanagisawa
}

Key words: vaginal amebiasis, cervical cancer

(Intern Med 55: 3071-3072, 2016)

(DOI: 10.2169/internalmedicine.55.7289)
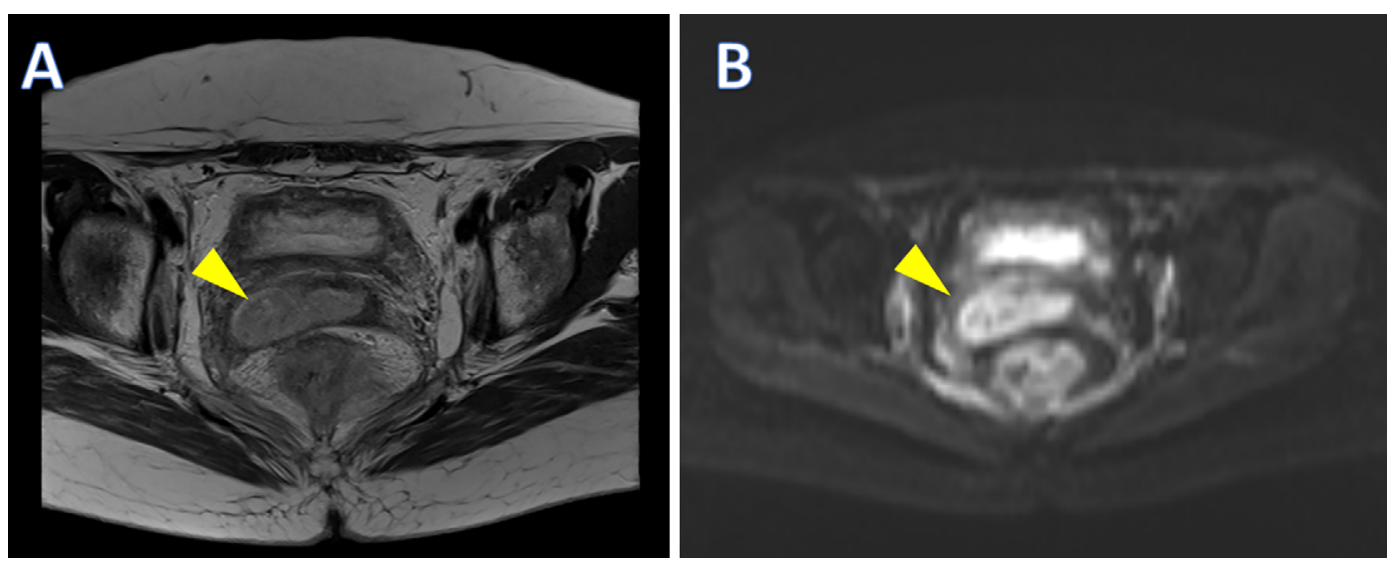

Picture 1.
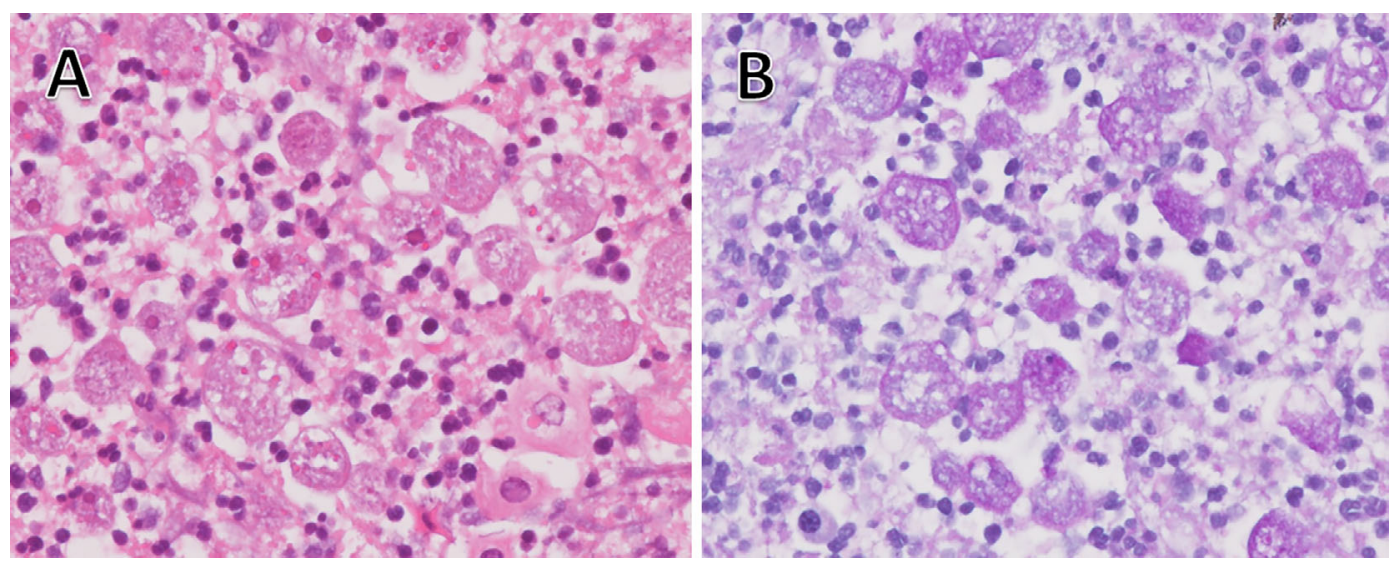

Picture 2.

A 46-year-old woman presented with lower abdominal pain, diarrhea and irregular vaginal bleeding persisting for the past 2 months. She had a history of cervical cancer treated with concurrent chemoradiotherapy 6 years previously, which was successful. Magnetic resonance imaging with T2-weighted and diffusion images showed a high inten- sity area in the cervix, suggestive of recurrent cervical cancer (Picture 1). However, a biopsy specimen of the cervix was compatible for amebiasis on hematoxylin/eosin and periodic acid-Schiff staining (Picture 2). A stool specimen demonstrated an ameba trophozoite, which was later confirmed to be Entamoeba histolytica. Blood tests were nega-

Department of Infectious Diseases, Tokyo Metropolitan Komagome Hospital, Japan

Received for publication February 17, 2016; Accepted for publication February 23, 2016

Correspondence to Dr. Naoki Yanagisawa, naokiy-97@umin.ac.jp 
tive for HIV, syphilis, and hepatitis B, but positive for hepatitis C. Treatment with metronidazole resulted in a rapid clinical response. Vaginal amebiasis may mimic symptoms and imaging findings of cervical cancer $(1,2)$. Physicians must be aware of this rare disease, and a tissue biopsy is essential to make an accurate diagnosis.

The authors state that they have no Conflict of Interest (COI).

\section{References}

1. Arvind A, Minakshi B. Cervical amoebiasis mimicking cervical carcinoma, a rare presentation of a common infection. J Infect Public Health 2015 (in press).

2. Antony SJ, Lopez-Po P. Genital amoebiasis: historical perspective of unusual disease prsentation. Urology 54: 952-955, 1999.

The Internal Medicine is an Open Access article distributed under the Creative Commons Attribution-NonCommercial-NoDerivatives 4.0 International License. To view the details of this license, please visit (https://creativecommons.org/licenses/ by-nc-nd/4.0/).

(C) 2016 The Japanese Society of Internal Medicine http://www.naika.or.jp/imonline/index.html 